\title{
ERP System Implementation At A Small Engineering Company: Size Does Matter
}

Vance Cooney (E-mail: vcooney@mail.ewu.edu), Eastern Washington University

Pamela Pratt (E-mail: pam.pratt@sdl.usu.edu), Utah State University

David Olsen (E-mail: dolsen@b202.sus.edu), Utah State University

\begin{abstract}
This case regards a company pseudonymously referred to as Johnson Precision Instruments, Inc, that, faced with Y2K compliance, decided to deal with it by adopting Oracle's ERP solution, Oracle Applications.

As recently as the mid to late nineteen eighties, traditional business applications comprising an organization's information infrastructure used data that either resided in proprietary file structures or was easily represented by the relational database model, in either event resulting in an ever proliferating set of non-integrated, heterogeneous systems. In today's business climate, access to information is key to competitive advantage, but both data and IT architectures have become increasingly complex, so a single system model is currently deemed desirable to reduce or eliminate the deleterious effects associated with the proliferation phenomenon. This single system model (that would serendipitously solve as Johnson Precision Instruments, Inc.'s (JPII) Y2K problem as well) is typically embodied in the implementation of the Enterprise Resource Planning (ERP) process, but this solution carries it's own costs and risks as this case makes clear.
\end{abstract}

\section{Introduction}

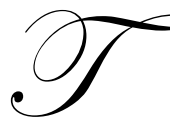

his article discusses the case of Johnson Precision Instruments, Inc.'s (JPI) travails in adopting an Oracle based Enterprise Resource Planning (ERP) solution. JPI is a Sparks, NV based corporation that, at the time of this writing (spring / summer 2003), had annual revenues of $\$ 20$ million and 200 employees world wide. In the late 1990s JPI, like many other similarly situated companies, was looking at dealing with the Y2K problem in its many information systems and was investigating the desirability of resolving this problem and, at the same time, updating and consolidating its IT resources by way of ERP $(2,7,15)$.

We begin by reviewing JPI's corporate history and background. Then we will discuss the definition of ERP systems, ERP selection and implementation considerations and the ERP services market. Next we look at the circumstances that lead JPI to consider an ERP solution and the how's and why's of JPI's selection process. Finally, we will detail JPI's ERP implementation experience and assess the results; additionally, we will discuss the implications of the implementation to JPI as a guide to other organizations with similar needs and resources.

Disclaimer: The names of the principals, as well as the identity of the business and it's location(s) have been altered in the article to respect the privacy of all concerned. Requests for references sourced to the actual company should be addressed to the authors.

\section{Background}

\subsection{JPI Corporate Background And History}

JPI is a major manufacturer of data acquisition systems, including high-end weather station hardware and software, on-site data retrieval systems, data storage modules and measurement and control devices known as data- 
loggers, the company's flagship offering. They also offer power supplies and solar panels, environmental sensors and a full range of telecommunication options that allow interrogation of a datalogger from a remote computer (1).

JPI was organized in 1974 by Dean and Derek Johnson with initial capital from themselves, six brothers, and their father, Bernard Johnson. Dean Johnson's background is in physics and electrical engineering. While working his way through school he founded Sparks Precision Instruments, a company that dealt in electronic soil sensors which he subsequently sold to finance his education. Derek Johnson's background is similarly technical and concentrated on mechanical design and manufacturing engineering. Both Dean and Derek attended Nevada State University in Sparks, NV (2).

The brothers marketed their first product in 1974. Known as the Model EA11 Path Averaging Laser Anemometer, it was an instrument used for measuring the force and speed of wind. This was followed in 1975 by the ET7 digital recorder. It was the first portable battery- operated datalogger using CMOS technology that could collect time-averaged measurements from thermocouples, solar radiation sensors, and wind sensors requiring vector averaging. It was well received by agricultural researchers and over 500 systems were sold $(2,7)$.

By 1978 JPI had grown to 20 employees and had reached \$1 million in annual sales. 1981 saw JPI move to its current, much larger location, also in Sparks, Nevada. Here company technicians developed a radio frequency (RF) modem that enabled two-way communication using very high frequency, or ultrahigh frequency, and tested it, together with it's datalogger in northern Nevada during the winter of 1984 and 1985. The datalogger and RF Modem were used on Mt Virginia Peak (10,100 ft) and at the Sutcliffe Depression, located near Lake Sutcliffe. That winter, a temperature of minus 70.5 degrees Fahrenheit was recorded reflecting the extreme conditions the unit had to contend with. In 1988, a wind study was conducted where each station made measurements once per second, computing one minute averages. A central computer interrogated 30 stations via radio every 15 minutes for three weeks resulting in about 10 million values with $100 \%$ data recovery. It lead to a key element in a system of 140 portable weather stations currently operated by the National Atmospheric Testing Laboratory at Los Alamos in New Mexico.

Since its founding, JPI has continually developed new dataloggers, data acquisition systems, and measurement and control products that are used worldwide. JPI's continuing emphasis on improving quality and dependability, reflected in their current self certification to ISO 9001 compliance and anticipated external certification in Fall, 2003 , has created products that reliably measure nearly any type of weather under almost any conditions and are used worldwide $(1,2,7)$.

JPI went international in 1985, establishing a subsidiary in England to serve the European market, and in 1993 JPI established another subsidiary in Australia to serve the South Pacific and Southeast Asian markets. Today they are recognized as a major player in the remote sensing niche market.

\subsection{Enterprise Resource Planning Systems}

According to Christian Vogt, an ERP is defined by "any software system designed to support and automate the business processes of medium and large businesses." (15). ERP can also include application modules for the finance and human resources aspects of a business. Typically, an ERP system uses or is integrated with a relational database system" (13).

Regardless of the details of the definition of ERPs, it is clear that they are software in support of a very popular information systems / information technology driven process. The objective of that process is to integrate information from across all organizational departments and organizational information systems into one computer system that typically shares one database. The popularity of this approach is driven by the fact that, in organizations that do not deploy ERP systems, each department may store and maintain its data in different ways such as individually managed databases, file and application systems, etc., replicating the same data elements (for instance employee and customer data) many times throughout the company. 
Technologically, ERPs trace their provenance all the way back to the manufacturing systems of the 1960s. These were inventory control systems that functioned to reflect available stock on hand. By the 1970s materialsrequirement-planning systems (MRPs) appeared that, given a master production schedule and bill of materials, could forecast materials needed and schedule inventory replenishment . Manufacturing-resource-planning systems (MRPII) supplanted MRP systems in the 1980s providing not just inventory support but planning support for virtually every facet of a manufacturing enterprise from financial planning to personnel planning to providing what-if scenario support (15). This clearly sets the stage for the ERP concept which extended these capabilities beyond just manufacturing venues. Nonetheless ERP systems often times show their manufacturing roots $(11,15)$.

Actual identified ERP systems have been deployed since the mid-1970s on mainframes. The client server (C/S) architecture resulting from the advent of the PC in the late 1970s supported the advent of ERPs based on client server (C/S) architectures since the early 1980s, resulting in far more attractive pricing (5). The adoption by smaller firms of ERP solutions is no doubt linked to this development. Additional drivers to adoption include the desire for richer representations (i.e., data was stored in Java and $\mathrm{C}^{++}$data structures as objects requiring object-to-relational mapping software) and complex multimedia documents requiring analogous conversion (7).

Consequently, a single system model, with a central database where all data types already reside, such as an ERP, can reduce or eliminate and complex document-management systems and object-to-relational mapping software as well. These are strong selling points and in the late 1990s there was one additional consideration that sparked a wave of adoption: Y2K. Because ERP systems are relationally databased they make dealing with the kind of re-coding problems a company like JPI would have easier to deal with at the time and less likely to recur than in less flexible legacy systems. JPI was attracted to the ERP concept for all these reasons.

\subsection{ERP Vendor Environment}

The ERP vendor environment is highly competitive and very volatile; there are over 100 different vendors that currently offer ERP products. The largest players are SAP, Oracle, PeopleSoft, Baan and J.D Edwards (5). To give a sense of the size of this industry, SAP, the largest player in the market with approximately $32 \%$ (10), had revenues in 2002 of $\$ 7.8$ billion (6).

Their products generally contain a core set of applications. These core applications include human resources, product management, accounting, and manufacturing. Many of the large vendors add more applications, including business intelligence / data warehousing, supply chain management (SCM), and customer relationship management (CRM) (5).

Several trends appear to be dictating the evolution of ERP and hence the competitive environment: (a) improving integration and hence flexibility of information systems (IS), (b) embracing e-commerce, (c) reaching out to new users, and (d) adapting to the Internet (5).

The first trend, improving integration and flexibility, is really the cornerstone of ERP. The more easily a vendor's approach migrates or integrates these divergent systems for the Information Technology (IT) department the more appealing the offering (op. cit.).

The second ERP trend is embracing e-commerce. With the dot com boom, many people thought the ERP movement would fade away through the combined effects of ERP implementation horror stories and the plethora of internet based solutions to some of the same organizational IS areas of concern addressed by ERP. In response to that threat, ERP vendors have made it possible to tie e-commerce applications to ERP systems.

The third ERP trend is reaching out to new users. Traditionally, only upper management used ERP systems, but as the potential of increased savings and revenues from providing ERP resources to lower levels in the organization became apparent, their user base began to grow. This expansion includes mobile workers and multienterprise users (i.e., other 'partnered' company's employees). More and more organizations are forming alliances that include data sharing. An example would be the alliance formed to between Procter and Gamble Corp. and 
Kroger Corp. whereby their information systems are to some extent integrated and through the actualization of the methodology called Efficient Consumer Response (ECR) Procter and Gamble is able to "see" sales in real time at Kroger grocery stores and be able to plan inventory levels appropriately. ERP systems facilitate such designs and competitive advantage accrues to both participants making this a very attractive and use of the methodology $(3,14)$.

The final trend in ERP is adapting to the Internet. With technologies such as http, Java, XML to name a few easy communication of data structured any way the user desires has become the norm. An internet enabled ERP system can extend the organization's reach globally within a company and, Internet enabled easy to use web interface's allow creation of a consistent interface, reducing learning time and training costs, one of the major factors in IT overall cost (5).

\section{The JPI Expereince}

\subsection{Johnson Precision On The Verge - The Situation At JPI In The Late 1990s}

A "legacy system" is defined as an IT structure that is functioning in a company but that is neither optimal for the needs of the company nor is it easily modifiable for project purposes (8). The main problem with legacy systems is that they are tightly woven into business operations which creates a major obstacle when implementing a new ERP system; legacy systems were one of the primary obstacles to Y2K compliance at the turn of the last century (op. cit.).

JPI had been using such a legacy system for years. Built in-house, its system, known as SAM was used to track system data for storing and retrieving engineering documents from the document library, which was also built in-house. The B+ tree file access system was not Y2K compliant and would not support the company's efforts after the turn of the century. The pressures of Y2K compliance, coupled with the lack of integrated systems in general, caused JPI to begin looking into ERP solutions in 1997 and 1998 (7).

\subsection{JPI's ERP Selection And Implementation Approach}

In interviews with management at JPI a surprisingly informal approach to selection was evident. The JPI Implementation Team did attend a number of technical enterprise planning conferences though in the interviews they could not specifically recall the different vendors but did recall discussing different ERPs such as JD Edwards and SAP. They did not generate a formal list of selection criteria prior to purchasing; "It was strange. They just seemed to have decided that this was the route they were going to take, period. JPI's IT section is not big and I got the impression that they didn't spend much time in evaluating the different ERPs." (7). At some point Oracle emerged as the choice. Another comment that emerged during an interview on JPI's satisfaction with their selection may indicate how this occurred; " ... product was oversold by the Oracle sales people and ... the Oracle implementation personnel should have and could have been more qualified." (7). Oracle has a reputation for having a very aggressive sales force and may have simply had the most presence during the selection process (4).

In any event, two managers were selected from each department that was intended to receive the Oracle implementation, forming the Implementation Team. Each of these managers met with their department personnel to develop an idea of specific types of functionality required.

Many Oracle and JPI personnel were involved with the ERP implementation. The system was installed in parallel to the SAM system over an eight month period. Implementation began in February of 1999 and was completed in September 1999 so that JPI would be Y2K compliant. The Oracle database is centralized and is only accessible from company headquarters in Sparks, NV. The ERP system runs on Sun Unix servers with the Solaris operating system(7).

The total cost of implementation was estimated to be around \$1.2 million, and each year JPI spends and additional $\$ 144,000$ for software licenses and $\$ 50,000$ for support fees. Comparing the actual price Johnson Precision paid for the system to the estimated savings, the return on investment of the system is believed to be negative. 
(The net present value was not estimated at the time of the purchase, so no projected cost savings exist to compare to the actual price of the system) (7).

\subsection{General ERP Selection And Implementation Guidelines}

Typically, organizations find themselves looking at ERP systems because they are driven to. They often reach a point where the expense of porting data from one noncompliant system to another reaches a level where it is noted by upper management. Even then, the decision to undertake an organizational transition to an ERP based infrastructure is not taken lightly. Selecting an ERP solution can be an immense undertaking. However, the historic drive downwards of cost owing to competitive adoption and experience has led smaller organizations to begin using these application packages as well in order to remain competitive / profitable.

Generally, companies select business applications on the basis of available features and the functionality of those features. Given the high cost (especially when factoring in risk) of ERP implementation, the selection criteria should be heavily weighted toward the ability of the application to serve the needs of the enterprise over a significant time period. Sprott suggests that companies should consider the following four criteria: applicability, integration, adaptability, and upgradeability — when selecting an ERP system. Applicability; The complexity of the application should be matched with the complexity of the business. It is not always the best solution to implement the "best-in-class" ERP. The selection should take into account the size of the company today and its potential growth in the future. Integration; The ability of an ERP system to integrate its own applications with other prepackaged and legacy systems is a fundamental decision factor. Ease of integration is also a key in determining the cost and time required to implement and hence effect change to business processes. The interface architecture of the core package (i.e., APIs) is a critical factor that can make integration significantly easier or more difficult. Adaptability; The extent to which an application changes to handle new circumstances is important as few organizations' operations, workforces, etc. will remain static in the future. And finally, Upgradeability; A major advantage of componentized applications is the ability to deal with the inevitable incremental release and upgrade process (12).

\subsection{Results Of The Oracle ERP Implementation At JPI}

Overall, the Oracle business application components of the ERP have been frustrating. Complaints include: difficulty in programming customization, the fact that business applications don't function as promised requiring additional training and consulting costs, and the fact that Oracle does not implement the upgrades so that while an upgrade to more current versions of the software might ameliorate the problem, JPI would be responsible for installing the upgrades and testing the results (7). Two specific examples from different Oracle modules illustrate how these concerns manifest.

The Projects module is an application for managing projects (9). This component of the Oracle business application is very similar to Microsoft Project, a project management software tool. JPI bought 30 licenses for Oracle Projects; however, JPI does not use the licenses because they do not function as expected; they use MS Project instead (7)!

The Discoverer module is a reporting application that actually extracts information directly from the database (9). Every Monday, a series of scripts are run that check for misspellings and upper/lower case errors. But for the actual reporting function, JPI personnel still use Paradox; this is perhaps a consequence of inadequate employee preparation and training (7).

\section{Conclusion}

From reviewing all interview responses, the picture that emerges is very mixed at best at JPI. The finance and manufacturing departments feel that the implementation has been a success. For example, before the Oracle installation, company employees used two different systems to calculate and to produce end-of-year financial statements, but now they use only one: the Oracle system. The database is resilient and performs exceptionally well. 
Marketing, on the other hand has had very poor results from the application modules they expect to support them.

And upper management is very disappointed. The feeling is that the Oracle salespersons oversold their product, and, unfortunately, management literally bought the hype. Rather than requiring the salespersons to demonstrate the products functionality, management took their word at face value. After conducting a minimal evaluation of the product, management approved the purchase of the Oracle package, assuming it was a good investment for the company. Later, however, management discovered that they had purchased a much larger system than the company needed and one that they estimate utilizes approximately $25 \%$ of the ERP software. According to their CFO, JPI will have this ERP for a minimum of 2-3 more years. After that, the company is considering migrating to more a more appropriate suite of business applications. They were not specific but they said they would look for "a set of business applications that would be suitable for a smaller company, that would better suit their needs." Such a conversion is believed to cost somewhere in the neighborhood of $\$ 120,000$.

\section{References}

1. Johnson Precision, I. 2002, posting date. Johnson Precision Inc. Measurement and Control Systems. Johnson Precision. [Online.]

2. Johnson Precision, I. 2002, posting date. The Johnson Precision Story. Johnson Precision, Inc. [Online.]

3. Cooney, V. 1998. ECR Presentation by Kroger, Inc. CEO Joseph A. Pichler. In V. Cooney (ed.), Cincinnti, $\mathrm{OH}$.

4. Heskett, B. July 14 2002, posting date. Meet the kinder, gentler Oracle. ZDNet. [Online.]

5. Mello, A. July 14 2002, posting date. Inside ERP: What you need to know. ZDNet. [Online.]

6. Poor's, S. A. July 6 2003, posting date. "Standard and Poor's SAP AG ADS Corporate Profile", Fidelity Investments. [Online.]

7. $\quad$ Pratt, P. 2003. Personal JPI Interviews, Sparks, NV.

8. Robertson, P. 1997. "Integrating legacy systems with modern corporate applications", Communications of the ACM 40:39-46.

9. Rogers, R., posting date. Oracle Flow Manufacturing: How Oracle Flow Manufacturing supports building to customer demand. Oracle Corporation. [Online.]

10. Satzinger, J. W., R. B. Jackson, and S. D. Burd. 2000. Systems analysis and design in a changing world, Cambrige, MA.

11. Scott, J., and I. Vessey. 2002. "Supporting community and building social capital: Managing risks in enterprise systems implementations", Communications of the ACM 45:74-81.

12. Sprott, D. 2000. "Enterprise resource planning: Componentizing the enterprise application packages", Communications of the ACM 43:63-69.

13. Unknown 2003, posting date. "ERP". searchSAP.com., [Online.]

14. Unknown, posting date. FMI Media Backgrounder - Efficient Consumer Response. FMI Media. [Online.]

15. Vogt, C. 2002. Workshop and conference summaries: "Intractable ERP: A comprehensive analysis of failed enterprise-resource-planning projects”, ACM SIGSOFT Software Engineering Notes 27:62-68. 


\section{Do Not Print This Page}

\section{REFERENCES}

1. Johnson Precision, I. 2002, posting date. Johnson Precision Inc. Measurement and Control Systems. Johnson Precision. [Online.]

2. Johnson Precision, I. 2002, posting date. The Johnson Precision Story. Johnson Precision, Inc. [Online.]

3. Cooney, V. 1998. ECR Presentation by Kroger, Inc. CEO Joseph A. Pichler. In V. Cooney (ed.), Cincinnti, $\mathrm{OH}$.

4. Heskett, B. July 14 2002, posting date. Meet the kinder, gentler Oracle. ZDNet. [Online.]

5. Mello, A. July 14 2002, posting date. Inside ERP: What you need to know. ZDNet. [Online.]

6. Poor's, S. a. July 6 2003, posting date. Standard and Poor's SAP AG ADS Corporate Profile. Fidelity Investments. [Online.]

7. Pratt, P. 2003. Personal JPI Interviews, Sparks, NV.

8. Robertson, P. 1997. Intergrating legacy systems with modern corporate applications. Communications of the ACM 40:39-46.

9. Rogers, R., posting date. Oracle Flow Manufacturing: How Oracle Flow Manufacturing supports building to customer demand. Oracle Corporation. [Online.]

10. Satzinger, J. W., R. B. Jackson, and S. D. Burd. 2000. Systems analysis and design in a changing world, Cambrige, MA.

11. Scott, J., and I. Vessey. 2002. Supporting community and building social capital: $\quad$ Managing risks in enterprise systems implementations. Communications of the ACM 45:74-81.

12. Sprott, D. 2000. Enterprise resource planning: Componentizing the enterprise application packages. Communications of the ACM 43:63-69.

13. Unknown 2003, posting date. ERP. searchSAP.com,. [Online.]

14. Unknown, posting date. FMI Media Backgrounder - Efficient Consumer Response. FMI Media. [Online.]

15. Vogt, C. 2002. Workshop and conference summaries: Intractable ERP: A comprehensive analysis of failed enterprise-resource-planning projects. ACM SIGSOFT Software Engineering Notes 27:62-68. 